\title{
Sabemos Mesmo Como Foi Que Aconteceu?: Entrevista com Lola Arias ${ }^{1}$
}

\author{
Giorgio Zimann Gislon \\ Universidade do Estado de Santa Catarina - UDESC, Florianópolis, Brasil \\ E-mail: giorgiogislon@gmail.com
}

\section{Resumo}

Na entrevista, realizada no Gorki Theater em Berlim, no final de março de 2019, Lola Arias discorre sobre suas concepções estético-políticas e sobre procedimentos de criação de teatro documentário e comenta, especialmente, as peças: Campo Minado, Mi vida después e What they want to hear.

Palavras-chave

Lola Arias. Teatro documentário. Campo Minado. Mi vida después. What they want to hear.
Abstract

In this interview realised in Berlin at Gorki Theater, on the end of 2019's March, Lola Arias affirms her aesthetical and political conceptions, she comments on documentary theatre creative procedures and she analises specially the plays: Minefield, My life after. What they want to hear.

Keywords

Lola Arias. Documentary theatre. Minefield. My life after. What they want to hear. 
Lola Arias é diretora, dramaturga e escritora argentina, já realizou projetos em diversos países, entre eles "Chácara $\mathrm{Pa}$ raíso" em São Paulo, em 2008. Atualmente, ela reside em Berlim e trabalha na peça Futureland. Nessa entrevista, realizada no Gorki Theater em Berlim, no final de março de 2019, Lola Arias discorre sobre suas concepções estético-políticas e sobre procedimentos de criação de teatro documentário e comenta suas peças: Campo Minado, Mi vida después e What they want to hear.

Campo Minado, de 2016, é uma peça sobre a Guerra das Malvinas atuada por seis ex-combatentes, três argentinos e três britânicos, que contam em cena como foi sua participação na guerra e como foram suas vidas antes e depois dela. Mi vida depués, de 2009, leva ao palco seis pessoas que nasceram durante a Ditadura argentina e cujas famílias tiveram diferentes participações nos acontecimentos da época, os atores são desde filhos de militantes políticos até filhos de repressores. What they want to hear estreou em 2018 e leva ao palco quatro imigrantes e uma alemã. Um dos imigrantes ainda está com seu processo de pedido de asilo em aberto e a peça conta como é esse processo.

\section{$\mathrm{O}$ que te move a continuar crian-} do? E, especialmente, a continuar trabalhando com não atores?

O que me move a seguir criando, para responder à pergunta grande, é a curiosidade. A curiosidade por tudo, por ver o que acontece, por me encontrar com as pessoas, por descobrir novas universos, por fazer coisas que pensei que não poderia fazer. É a curiosidade o que faz com que siga o movimento.

$O$ fato de que eu trabalhe a partir ou com

10 presente trabalho foi realizado com o apoio da Fundação de Amparo à Pesquisa e Inovação do Estado de Santa Catarina e da CAPES. pessoas que não são atores, ou que trabalhe a partir de histórias reais, ou pesquisas, é algo que é parte de forma como penso a arte. Mas não é que eu sempre trabalhe assim, também escrevo ficção e também escrevi obras teatrais completamente ficcionais. Não vejo uma coisa tão separada da outra. Meu trabalho como artista é um trabalho que às vezes é mais criar ficção, às vezes é mais documental, mas, na verdade, o que mais me interessa é esse encontro que se produz quando começo um projeto, começo uma pesquisa e mergulho numa aventura que é um mundo desconhecido, onde tudo é novo e onde tenho que aprender tudo de novo.

Os procedimentos de oscilação entre realidade e ficção são um desejo de desestabilizar as narrativas contadas anteriormente?

Acredito que em cada projeto há uma pergunta diferente da que se parte, às vezes os projetos se tratam de entender problemas. Quando fiz Mi vida después, queria entender porque minha geração está marcada pela história da Ditadura. Como nós, como geração, somos os que nascemos debaixo da nuvem da Ditadura e como isso determinou tudo. Nossa subjetividade, como pensamos, como escrevemos e como construímos nossa história tem relação com isso. Às vezes essa pergunta leva a desconstruir certas ideias das que se parte de como se deve contar essa história.

No caso de Mi vida después, - falo justamente de Mi vida después porque acabaram de se passar dez anos dessa obra - quando eu a fiz era impensável que a filha de um repressor fosse parte de um projeto assim. Todo mundo me dizia que isso era impossível, que não poderia colocar lado a lado na peça a filha de um desaparecido e a filha de um repressor. Eu dizia: "Mas é a filha, não é o pai!". 
A filha não é responsável que seu pai tenha torturado ou tenha se apropriado de uma criança nascida num Campo de Extermínio.

Agora, dez anos mais tarde, há uma associação de filhos de repressores que se declaram contra seus pais e que fizeram uma declaração pública de suas diferenças com relação aos seus pais, mas há dez anos era muito incomum colocar juntos num mesmo palco a filha de um repressor e a filha de um desaparecido. Para mim, esse foi o desafio, o risco que tomei fazendo essa obra.

Agora, quando estou trabalhando num novo projeto, há cada vez a ideia de trabaIhar sobre um problema diferente. Quando fiz What they want to hear, por exemplo, o problema que eu tentava abrir é como é esse processo de asilo. Quando todos dizem: "Ah, aqui vem todos esses refugiados a se beneficiar, a usar os recursos alemães.". Realmente qual o processo que eles tem que fazer? Como funciona a Lei de Asilo? Como funciona na União Européia toda? O que acontece? Como todas essas decisões políticas estão alterando as vidas de muitas pessoas? Pessoas que estão neste momento sem status, paradas, paralisadas, sem poder continuar com suas vidas. E, de alguma maneira, colocar em cena, reconstruir um processo de pedido de asilo, do princípio ao fim, era algo inédito. Porque isso é algo que sempre permanece nesse escritório fechado, nunca ninguém sabe o que acontece lá dentro, a não ser a pessoa que passou pelo processo. Abrir essa quarta parede, esse escritório, e mostrar como é esse procedimento palavra por palavra era algo que me interessava muito. Eu queria colocar em discussão como são esses processos pelos quais a vida de alguém fica presa na burocracia alemã. Então, é sempre um problema distinto que se há que abrir, analisar, e em cada obra há como uma pergunta diferente que se quer responder.

\section{Como são os procedimentos de entrevista?}

A primeira entrevista que tenho com alguém desconhecido é uma entrevista bem clássica, como poderia ser qualquer outra. No sentido em que eu pergunto e o outro responde e nessas perguntas eu vou construindo uma história dessa pessoa. Às vezes, eu tenho uma pergunta particular que me interessa e que repito a cada um dos entrevistados. Por exemplo, em Campo Minado era: "Qual a lembrança que permanece até o dia de hoje na sua memória? Conte-me uma coisa, não me conte toda a Guerra. Qual é a lembrança, qual a imagem, o momento, a situação, que volta como um flashback?" essa era a pergunta. Eu fazia uma entrevista de duas horas para conhecer a pessoa e isso estava em algum lugar, essa era a pergunta central. Mas, na verdade, o que eu acredito que é o mais interessante do trabalho no teatro é justamente algo que não é do trabalho de um pesquisador ou de um jornalista. É quando a entrevista se move a uma situação de jogo e de atuação em que essas perguntas são respondidas novamente em situações em que o entrevistado tem que improvisar. Nesse momento, aparecem coisas que, provavelmente, ninguém te diria sentado numa mesa, numa entrevista frente a frente. Mas diz e faz numa situação de um jogo: "Agora joga a bola e diz algo!", "Agora vocês três se jogam no chão e reconstroem uma situação", "Agora vá tocar uma música e diga uma lembrança que tenha relação algo que aconteceu.". Então, quando a entrevista se transforma num trabalho com o corpo, com a imaginação, com outros recursos, com outras pessoas, eles voltam a responder essas perguntas e aparecem novas respostas. Neste trabalho com os outros, com o corpo e com a imaginação é onde essa primeira entrevista que se fez vai se aprofun- 
dando e se começa a entender muito mais dessa pessoa e do que ela viveu, da sua experiência. No trabalho no tempo sobre o mesmo. Há algo do teatro que é repetição pura. Essa repetição vai criando níveis de profundidade no mesmo relato, se vai chegando mais longe e às vezes aparecem coisas que não se podia prever que estavam aí.

\section{- A repetição, segundo a psicanálise, é um elemento central do trauma. De que maneira você trabalha para levar os traumas ao palco, como faz, por exemplo, em Campo Minado?}

Nunca tive nenhuma formação como psicanalista eu mesma, mas sou filha da psicanálise porque faço terapia desde quando eu tinha treze anos. Ou seja, a ideia do relato e a repetição do relato, o encontro com outro e voltar a contar e pensar sobre a mesma coisa, é muito natural para mim porque eu experimentei eu mesma indo fazer psicanálise desde os treze anos.

No momento em que trabalho com o outro, para mim o trabalho é um trabalho onde se dá certas ferramentas para trabaIhar e se vai construindo uma distância entre a pessoa e esse relato. Esse relato que a princípio é, talvez na primeira vez que se conta, muito doloroso e faz chorar, na segunda vez que se conta, há uma distância que se vai adquirindo e, na terceira vez, se conta ao outro e o outro faz uma ação e há uma tela e se vai construindo uma distância que permite à pessoa transpor. Digamos, transpor a situação de dor e poder contá-lo como se fosse a história de um outro.

Para mim, isso é o que vai produzindo o teatro e a repetição, a possibilidade de distanciar-se da própria experiência. Percebê-la como uma história. Esse trabalho, seguramente, é um trabalho gradual, onde não apenas eu ocupo um lugar, mas também o grupo. No sentido de que o grupo é um suporte, o fato de que todos viveram uma experiência similar, todos são veteranos da guerra, todos entendem algo, isso produz um amparo muito importante para as pessoas. Por isso é muito importante o grupo, como numa terapia de grupo, porque o grupo é o que sustenta essa pessoa que está passando por esse processo de compartiIhar, o que significa isso e tudo mais. Mas não tenho uma técnica, é bastante intuitivo o que faço, no sentido de até onde vou.

\section{Talvez uma ética?}

Sim, a ética é que tudo que acontece no ensaio fica dentro do ensaio, essa é a ética. Que esse é um lugar totalmente livre, de imaginação, de dizer o que seja, de chorar, de gritar, de lutar, de tudo mais. Mas é este lugar fechado e nós decidimos o que vai ser levado para fora. Que em geral é vinte por cento de tudo que se conta, se diz, se compartilha no ensaio. Nesse ponto, funciona como a terapia ou como a confissão, com o padre na Igreja. Isso que passa aqui dentro é o nosso segredo e só compartilhamos o que quisermos compartilhar.

\section{Como funciona a autoria no teatro documentário?}

O que acontece é que a história, quando alguém conta, é muito simples, assim, se torna um trabalho de escrita. Eu sou, antes de tudo, uma escritora e de fato escrevi poesia, ficção, contos, antes de escrever teatro. As pessoas acreditam que porque é documentário é simplesmente assim, tu toma o que o outro disse e o escreve tal qual ele disse, como se fosse a entrevista de um jornalista, depois coloca em seguida o que disse o outro e por isso não há nenhuma autoria, porque somente pusesse um texto ao 
lado do outro, fizesse copiar colar de tudo que se disse. Mas não, há uma reformulação de tudo que se disse. Quando alguém te conta a história de como se afundou o Belgrano e demora duas horas para contar toda essa história e você precisa transformar numa cena de dois minutos, o que você faz? A escreve, a ficcionaliza, a reformula. A converte em texto. Isso é a minha autoria. Esse trabalho. $O$ trabalhar com cada uma dessas experiências e transformá-las num texto, num texto belo, com certas imagens, que seja poderoso, que tenha força, que seja sintético, isso é um trabalho de escrita.

Eu acredito que há um não reconhecimento da autoria do texto no teatro documentário por ignorância, por pensar que é simplesmente copiar e colar de entrevistas. Mas é um trabalho de escrita completo, o mesmo que eu teria para escrever uma obra de teatro ficcional, tenho que escrever a obra completamente, do princípio ao fim dessa escrita. Simplesmente está baseada na experiência de algumas pessoas e essas pessoas me contaram coisas. Porém, essas coisas como as contaram e as palavras que usaram se reformula completamente para que funcione como texto e como se cruzam nas cenas e porque essa história se conta enquanto se faz outra coisa ou tal outra. As ações que estão envolvidas, tudo isso é trabalho da dramaturgia e é um trabalho muito preciso.

Quando digo que é uma decisão de todos, é que é uma decisão de todos no ponto em que eu não vou escrever algo que o outro depois não queira dizer, não vou escrever algo que depois o outro não queira contar ou com que não concorde. Porque precisa sentir-se representado por esse texto, de maneira diferente de um ator que não precisa concordar com o texto, somente precisa dizê-lo. Nesse caso, eles precisam estar de acordo. Essa é a grande diferença e isso é o que faz, ademais, com que as obras funcionem ao longo do tempo, porque se eles estão concordando e convencidos das coisas que dizem e que fazem, então, podem sustentar a obra. De outro maneira, não poderiam fazê-la uma e outra vez.

\section{Estão enganados, então, aqueles que pensam a dramaturgia do teatro documentário como colagem?}

Eu acredito que o problema de pensá-lo como colagem é que parece que a única coisa que você faz é copiar e colar. Não é copiar e colar. É preciso reescrevê-lo, é preciso reformulá-lo. Não funciona como o outro conta. Não funciona para o que você quer em cena. $E$ também tem que reescrevê-lo de maneira que seja possível ao outro dizê-lo, também é necessário recuperar certas palavras que o outro disse, é preciso recuperar certas coisas. Às vezes, se toma o que o outro diz como uma citação textual. Mas te diria que é a menor parte.

\section{Se pensa o procedimento também como ready-made...}

Se pensa não, eu acredito que o Rimini Protokoll inventou uma forma de chamar o que eles faziam, ready-made, especialistas do cotidiano, mas isso não se aplica a todo mundo que trabalho dentro do gênero documentário. Porque é um gênero e já está na hora de que seja aceito como um gênero. Assim como no cinema existe o cinema de ficção e o cinema documentário, agora cada vez mais é muito ambíguo esse cruzamento, há muitos filmes que é muito difícil de definir se são documentais ou ficcionais, o que se situa onde. Eu acredito que no teatro se passa exatamente o mesmo. O que acontece é que durante muito tempo o teatro documentário era, o que na Inglaterra é chamado de Verbatim Theatre, o teatro que 
estava baseado em entrevistas ou pesquisas, porém, feito por atores. A diferença, o que começa a abrir outra possibilidade dentro do teatro é quando se diz: "Bom, não somente queremos os testemunhos para colocar na boca dos atores, queremos as pessoas como parte desse teatro". Alguns chamaram isso de teatro comunitário ou teatro do oprimido, como dizia Boal. Mas, de alguma maneira, todos estavam fazendo um trabalho com pessoas que não eram atores, que iam contar experiências pessoais.

O que acredito que o Rimini faça é, nesse sentido, criar uma forma de falar desse trabalho, que corresponde exatamente ao que eles fazem. E que não se pode aplicar a todas as outras formas de teatro que trabalham documentalmente ou a partir de pesquisas.

\section{Como pensa a relação entre as} memórias pessoais e a memória coletiva?

Para mim o que há em Mi vida después como um ponto de início no meu trabalho é que há algo da memória que uma pessoa tem sobre certo episódio da história, nesse caso a Ditadura, que aparece como colocada em questão por esse novo relato polifônico dessas pessoas. Mas acredito que o que mais acontece nas obras é produzir essa espécie de viagem no tempo no qual os espectadores, e também os performers, voltam atrás. Isso se passa tanto aos espectadores como aos performers, no sentido que cada um se pergunta onde esteve durante a Ditadura, o que fizeram seus pais e o que aconteceu. Há algo disso, de fazer essa viagem juntos. Mas isso funciona em algumas obras, funciona em Mi vida después, funciona em Campo Minado e funciona em relação aos países, funciona em relação a Inglaterra e Argentina, isso de juntos recordarmos o que aconteceu durante a guerra. Em outras obras, eu acredito que funciona diferente.

Em What they want to hear, não é que o espectador está voltando na sua própria lembrança porque é a história desse refugiado, mas o que está é voltando atrás no tempo e pensando: "Ah, nesse momento quando eu via todas essas imagens dos refugiados cruzando a Estação Central de Munique, ele estava ali". Há algo dessa imagem abstrata das notícias que se torna muito real e essa pessoa que parece um outro, o outro, o refugiado, o diferente, se torna uma pessoa igual, como alguém que tem uma família, um curso universitário, quer ir estudar na sua Universidade e precisa coletar assinaturas em alguns papéis, que ninguém dá. Há um processo, nessas obras, de identificação, de deixar de ver essa pessoa como a figura de refugiado, como algo abstrato e passar a ver essa pessoa, essa história, de modo muito concreto, muito real.

\section{- Como é ser uma diretora argentina} na Alemanha?

Há muitos que teorizaram o estrangeiro, creio que Georg Simmel fala do artista como o estrangeiro, como alguém que vem de fora pode trazer um olhar diferente às coisas. Às vezes acredito que sim, que, em certos projetos, para mim serviu muito ser totalmente estrangeira ao problema, totalmente ignorante, não saber nada. Me serviu muito para ter um olhar sem preconceitos, no sentido de que tudo eles tinham que me explicar. "RDA, me diz o que é a RDA. Sim, tratem de explicá-la a alguém que não entende nada, como foi?". Essa posição é estratégica, eu te diria, porque coloca o entrevistado a pensar sobre coisas que supostamente todos já sabem como foi. "Ah sim todos já sabem, mas como era?". Com o trabalho no Chile também acredito que me serviu muito, quando fiz El año en que nascí, fui da Argentina e tiveram que 
me explicar quem eram, como foi. Há algo disso, de não saber nada, que é muito bom como estratégia de chegar a um problema. Porque precisa aprendê-lo do zero. Além do mais, como não sabes nada, não tem isso, que eu acredito ser o problema maior de todos, que é acreditarmos que já sabemos. Por isso, não perguntamos, não questionamos e não debatemos as coisas porque acreditamos que são óbvias. "Bom, já sabemos como era a RDA". Sabemos? não, eu não sei. "Já sabemos como foi a Ditadura Chilena, já sabemos o aconteceu.", sabemos? eu não sei. "Já sabemos o que acontece com um refugiado, já escutamos toda hora as notícias". Sabemos o que acontece a um refugiado? Sabemos como é o processo?

\section{— Há uma diferença no público ale- mão em relação ao latino-americano?}

Agora já faz dez anos que faço trabaIhos na Alemanha, já estou acostumada. A princípio, quando comecei a assistir teatro alemão, me surpreendia a ironia, como algo de estar sempre por cima das coisas, a ironia do teatro alemão. Sempre tinha a sensação que estava vendo que esses performers, que estavam aí, estavam por cima do problema, por cima do texto, por cima da situação e eram irônicos, sarcásticos, comigo, com o público e com o outro. Isso vindo da forma de teatro que eu conhecia me chamava a atenção. Não porque não conhecíamos o humor ou a distância, eu havia me formado com Ricardo Bartís, entre outros. Mas a posição, para mim, era uma posição nova, de sentir-se quase que inferior ao que está em cena, como uma espécie de ironia que mostrava a superioridade do que estava do outro lado do palco. Isso foi o que mais me surpreendeu. Depois de dez anos trabalhando aqui, também vejo que há muitas formas muito distintas de trabalhar e de fa- zer teatro e de estar em cena na Alemanha.

\section{Isso de alguma maneira influencia no seu trabalho?}

Não, faço o que eu quero fazer. Aquilo foi o que mais me surpreendeu. $O$ trabalho na Europa o que deu para o tipo de trabalho que eu faço foi uma infra-estrutura. Uma infra-estrutura que me permitia trabalhar com as questões que me interessam de uma maneira mais protegida, onde eu podia dar às pessoas com que eu trabalhava um salário, um sustento, uma instituição, que lhes contratava, que lhes dava suporte. Isso foi muito importante para os trabalhos que eu queria fazer. Eu trabalhei com gente que estava na rua, com crianças búlgaras, crianças alemãs e com refugiados. Eu precisava de uma instituição que dissesse: "Nós acolhemos o projeto, nos ocupamos de que essas pessoas possam fazê-lo, Ihes damos um salário, Ihes damos um espaço". Isso é muito importante e não existe na Argentina. Lá isso é muito, muito raro, é muito difícil de conseguir esse apoio. É uma cultura muito independente, com o mal disso também para o tipo de trabalho que eu faço. Quando eu trabalhei com os veteranos argentinos e ingleses, não tínhamos um teatro que amparasse o projeto e ensaiávamos num galpão totalmente inoficial, sem recursos, sem nada e sem também uma estrutura ao redor. Quem apoiava o projeto eram os festivais internacionais europeus. Não havia ninguém lá, como uma instituição, que dissesse: "Nós estamos aqui, nós vamos ajudá-los, resolveremos os seus problemas.". 
- No Brasil, Bolsonaro foi eleito e em vários países há um crescimento da extrema-direita. Como podemos pensar as formas teatrais em tempos de fascismo?

Eu acredito que também nos aconteceu na Argentina com Macri em outra escala. Claro que a direita que representa Bolsonaro é uma direita que vem com racismo, com homofobia, com tudo, como extrema-direita. Eu acredito que a estratégia é a estratégia do diálogo, de abrir espaços de conversa, de intercâmbio. Obviamente, que se precisa lutar, mas se precisa lutar tratando de escutar. De escutar: por que alguém me diz isso? Por que há associações de gays que apoiam a Bolsonaro? O que acontece na sociedade? O que está acontecendo? O que falta? Que linhas de solidariedade se romperam? Temos que gerar espaços de travessia. Não de afastamento.

Na Argentina, havia essa metáfora do fosso. Na Argentina, desde que assumiu Macri, se fala do fosso, como se houvesse um buraco e dois lados. Essa metáfora está nos destruindo, porque é uma metáfora muito separadora, que há uns e outros, que há os bons e os maus. E justamente, por exemplo, em debates como o do aborto, houve alianças entre partidos, que são de lados distintos do fosso, para apoiar essa lei na Câmara, que depois foi rejeitada no Senado. Mas a única maneira de conseguir certas coisas é produzindo aliança, pensamento, travessia, debate. Com o fosso não, as pessoas somente caem dentro dele.

Recebido: 24/04/2019

Aprovado: 30/10/2019 